
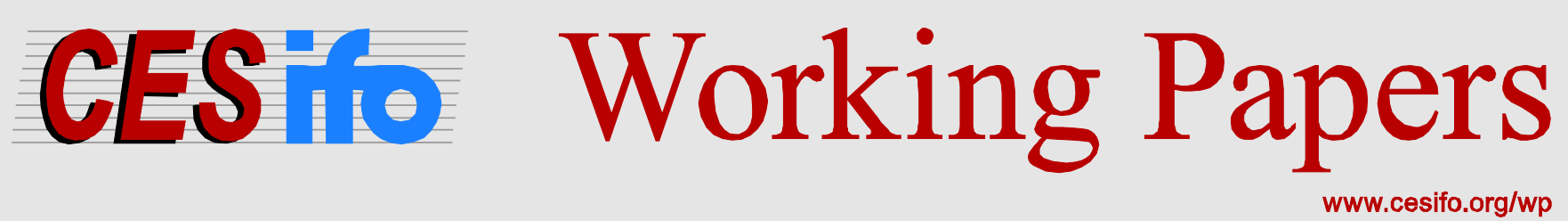

\title{
Salience, Competition, and Decoy Goods
}

\author{
Fabian Herweg \\ Daniel Müller \\ Philipp Weinschenk
}

CESIFO WORKING PAPER NO. 6168

CATEGORY 13: BEHAVIOURAL ECONOMICS

NOVEMBER 2016

An electronic version of the paper may be downloaded

- from the SSRN website:

- from the RePEc website:

- from the CESifo website:

WwW.SSRN.com

www.RePEc.org

www.CESifo-group.org/wp 


\title{
Salience, Competition, and Decoy Goods
}

\begin{abstract}
We consider a brand manufacturer who can offer, next to its high-quality product, also a decoy good and faces competition by a competitive fringe that produces low quality. We show that the brand manufacturer optimally provides a decoy good to boost the demand for its main product if consumers' purchasing decisions are distorted by salient thinking. The optimal decoy good is designed such that the superior quality of the brand manufacturers' main product and the unattractive feature of the fringe product are salient.
\end{abstract}

JEL-Codes: L130, L150, D030, D210.

Keywords: competition, decoy good, salience.

\author{
Fabian Herweg \\ University of Bayreuth \\ Faculty of Law, Business and Economics \\ Universitätsstraße 30 \\ Germany - 95440 Bayreuth \\ fabian.herweg@uni-bayreuth.de
}

\author{
Daniel Müller \\ University of Würzburg \\ Chair for Contract Theory and Information \\ Economics, Stephanstraße 1 \\ Germany - 97070 Würzburg \\ daniel.mueller2@uni-wuerzburg.de
}

\author{
Philipp Weinschenk \\ University of Kaiserslautern \\ Chair for Microeconomics \\ Gottlieb-Daimler-Straße \\ Germany-67663 Kaiserslautern \\ weinschenk@wiwi.uni-kl.de
}

This version: October 24, 2016 


\section{Introduction}

There exists a large literature in marketing and psychology that investigates the socalled decoy effect, which was first identified by Huber, Payne, and Puto (1982). The idea is that an extension of the product line may boost the sales of already existing products because "adding a new brand to the choice set can raise the choice likelihood or the attractiveness of one of the existing alternatives" (Huei-Chen and Wen-Liang, 2011, p. 235). This point is nicely illustrated by the following example from Ariely (2008):

\begin{tabular}{llr}
\hline Economist.com offers & Price \\
Option 1 & Web subscription & $\$ 59$ \\
Option 2 & Print subscription & $\$ 125$ \\
Option 3 & Print + web subscription & $\$ 125$ \\
\hline
\end{tabular}

Table 1: Subscription offers by The Economist. Source Ariely (2008).

Why would The Economist offer Option 2, that is dominated by Option 3? In an experiment with MBA students, when only Options 1 and 3 were offered, 68\% choose Option 1 and only 32\% Option 3. When all three options were offered, $84 \%$ selected Option 3 and only 16\% Option 1 . Adding a dominated option to the existing product line can change valuations for previously available options. The preferences of the MBA students thus seem to violate the axiom of independence of irrelevant alternatives. ${ }^{1}$

As is shown by Bordalo, Gennaioli, and Shleifer (2013), decoy effects can be explained by their theory of salient thinking. ${ }^{2}$ However, Bordalo, Gennaioli, and Shleifer (2013) do not analyze the strategic behavior of firms, i.e., when it is profitable for a firm to offer a decoy good and how it is optimally designed. We build a simple model where a brand manufacturer competes against a competitive fringe for consumers that differ in their marginal willingness to pay for quality. We show that if consumers are salient thinkers, the brand manufacturer, who offers a good of superior quality, can always increase its demand by offering an appropriate decoy

\footnotetext{
${ }^{1}$ See Angner (2012) for a textbook treatment of this example. Further examples are presented by Tversky and Simonson (1993).

${ }^{2}$ Experimental evidence supporting the theory of salient thinking à la Bordalo, Gennaioli, and Shleifer (2013) is provided by Dertwinkel-Kalt, Köhler, Lange, and Wenzel (2016).
} 
good, which in equilibrium is not chosen by any consumer. Moreover, the optimal decoy good makes the high quality of the brand product salient and highlights the price - i.e., the unattractive feature - of the competing fringe product.

In a recent working paper, Adrian (2016) analyzes a monopolistic two-type screening model where consumers are salient thinkers. If the monopolist sells only one product - either because it pools both types or excludes the low-type consumers it can also offer a decoy good. The monopolist always does so in this cases in order to make quality salient in the market. In our model, in contrast, the optimal decoy makes quality salient only for the brand product, but not for all products. Moreover, our brand manufacturer faces competition, whereas the monopolist in Adrian (2016) can directly choose the consumers' full consideration set. ${ }^{3,4}$

\section{The Model}

We consider a market where a brand manufacturer competes against a competitive fringe. The fringe produces a good of quality $q_{f}>0$ at constant marginal cost $c_{f}>0$, which is sold at price $p_{f}=c_{f}$. The brand manufacturer produces a good of superior quality $q_{b}>q_{f}$ at constant marginal cost $c_{b}>c_{f}$. The quality of the fringe product is assumed to be not too low in comparison to the brand product's quality, $2 q_{f}>q_{b}$. The brand manufacturer can introduce an additional good, a socalled decoy good. We assume that introducing this decoy good is costless, whereas its actual production is prohibitively costly. The sole purpose of the decoy good is to distort consumers' preferences, as the brand manufacturer does not want the decoy good to be purchased in equilibrium. If a decoy good is offered, the brand manufacturer is free in the choice of the decoy's quality $q_{d} \geq 0$ and price $p_{d}$.

There is a continuum of consumers of mass one. Each consumer is interested in buying one unit of the good, either the brand's or the fringe's product. Consumers differ in their marginal willingness to pay for quality, which is reflected by the parameter $\theta \in[\underline{\theta}, \bar{\theta}]$, with $0<\underline{\theta}<\bar{\theta}$. Let $G:[\underline{\theta}, \bar{\theta}] \rightarrow[0,1]$ denote the cumulative distribution function of $\theta$, which is assumed to be continuous. Absent any distor-

\footnotetext{
${ }^{3}$ Regarding applications to industrial organization, Inderst and Obradovits (2015) investigate practices like sales and loss-leader pricing in retail competition when consumers are salient thinkers.

${ }^{4}$ Dertwinkel-Kalt (2016) introduces the model of salient thinking into a health context.
} 
tions caused by salience, a consumer of type $\theta$ 's evaluation of good $\left(q_{k}, p_{k}\right)$, with $k \in\{f, b, d\}$, is

$$
u\left(q_{k}, p_{k} \mid \theta\right)=\theta q_{k}-p_{k}
$$

We refer to $\theta q_{k}$ as the "effective quality" of good $k$ for a consumer of type $\theta$.

We assume that consumers are salient thinkers according to Bordalo, Gennaioli, and Shleifer (2013). When evaluating a particular good, a salient thinker inflates the weight of the good's salient attribute. Whether the effective quality or the price of a particular good is salient is determined by how that good's value of the respective attribute compares to that attribute's average value in the consumer's choice set $\mathcal{C}$. Formally, let $\bar{q}_{\mathcal{C}}$ and $\bar{p}_{\mathcal{C}}$ denote the average quality and the average price in a given choice set $\mathcal{C}$, respectively. When evaluating product $\left(q_{k}, p_{k}\right)$, a consumer of type $\theta$ perceives effective quality to be salient if $\sigma\left(\theta q_{k}, \theta \bar{q}_{\mathcal{C}}\right)>\sigma\left(p_{k}, \bar{p}_{\mathcal{C}}\right)$ and she perceives price to be salient if $\sigma\left(\theta q_{k}, \theta \bar{q}_{\mathcal{C}}\right)<\sigma\left(p_{k}, \bar{p}_{\mathcal{C}}\right)$. Following Bordalo, Gennaioli, and Shleifer $(2013,2016)$, the salience function $\sigma$ is assumed to be symmetric and continuous and satisfies two main properties.

Assumption 1 (Ordering). For any $x, x^{\prime}, y, y^{\prime} \in \mathbb{R}_{\geq 0}$ with $[x, y] \subset\left[x^{\prime}, y^{\prime}\right]$, it holds that $\sigma(x, y)<\sigma\left(x^{\prime}, y^{\prime}\right)$.

Assumption 2 (Homogeneity of degree zero). For all $x, y \in \mathbb{R}_{\geq 0}$ and $\alpha>0$, it holds that $\sigma(\alpha x, \alpha y)=\sigma(x, y)$.

Assumption 2 implies that $\sigma\left(\theta q_{k}, \theta \bar{q}_{\mathcal{C}}\right)=\sigma\left(q_{k}, \bar{q}_{\mathcal{C}}\right)$ for all $\theta \in[\underline{\theta}, \bar{\theta}]$. In consequence, for a given product $\left(q_{k}, p_{k}\right)$ in a given choice set $\mathcal{C}$, the same attribute is salient for all consumer types - even though effective quality differs across consumer types. Moreover, according to Proposition 1 in Bordalo, Gennaioli, and Shleifer (2013), Assumptions 1 and 2 imply that whether all consumer types perceive the quality or the price of a given product $\left(q_{k}, p_{k}\right)$ in given choice set $\mathcal{C}$ to be salient is completely determined by how that good's quality-price ratio compares to the quality-price ratio of the reference good. ${ }^{5}$

In contrast to a rational consumer, who places equal weight on quality and price when evaluating a product $\left(q_{k}, p_{k}\right)$ in a choice $\operatorname{set} \mathcal{C}$, a salient thinker places higher

\footnotetext{
${ }^{5}$ Strictly speaking, this result requires that the considered good $\left(q_{k}, p_{k}\right)$ neither dominates nor is dominated by the reference good, i.e., $\left(q_{k}-\bar{q}_{\mathcal{C}}\right)\left(p_{k}-\bar{p}_{\mathcal{C}}\right)>0$.
} 
weight on the salient attribute:

$$
u^{S}\left(q_{k}, p_{k} \mid \theta, \mathcal{C}\right)=\left\{\begin{array}{lll}
\theta q_{k}-\delta p_{k} & \text { if } & \sigma\left(q_{k}, \bar{q}_{\mathcal{C}}\right)>\sigma\left(p_{k}, \bar{p}_{\mathcal{C}}\right) \\
\theta q_{k}-p_{k} & \text { if } & \sigma\left(q_{k}, \bar{q}_{\mathcal{C}}\right)=\sigma\left(p_{k}, \bar{p}_{\mathcal{C}}\right) \\
\delta \theta q_{k}-p_{k} & \text { if } & \sigma\left(q_{k}, \bar{q}_{\mathcal{C}}\right)<\sigma\left(p_{k}, \bar{p}_{\mathcal{C}}\right)
\end{array}\right.
$$

The parameter $\delta \in(0,1]$ reflects the degree of salient thinking, with lower values of $\delta$ representing stronger distortions from the rational benchmark. ${ }^{6}$ For $\delta \rightarrow 1$, the salient thinker converges to the rational consumer.

Finally, we assume that consumers' tastes are sufficiently dispersed such that in equilibrium both the brand manufacturer and the fringe have a positive market share.

Assumption 3. It holds that:

$$
\underline{\theta}<\frac{\delta c_{b}-c_{f}}{q_{b}-\delta q_{f}}<\bar{\theta}
$$

Assumption 3 implies that $\delta>c_{f} / c_{b}$, i.e., that the salience bias is not too strong.

\section{The Analysis}

\subsection{Demand for the Brand Product}

First suppose that the brand manufacturer offers only its brand product. The consumers' choice set then is $\mathcal{C}=\left\{\left(q_{b}, p_{b}\right),\left(q_{f}, c_{f}\right)\right\}=: \tilde{\mathcal{C}}$. Any profit maximizing price must be weakly higher than the brand manufacturer's production costs, such that $p_{b} \geq c_{b}>c_{f}=p_{f}$. Then, none of the two products is better in both attributes. With only two products in the choice set, by Proposition 1 of Bordalo, Gennaioli, and Shleifer (2013), the same attribute is salient for both products.

If $q_{b} / p_{b}>\bar{q}_{\tilde{\mathcal{C}}} / \bar{p}_{\tilde{\mathcal{C}}}$, quality is salient. A consumer of type $\theta$ purchases the highquality brand product if $\theta q_{b}-\delta p_{b} \geq \theta q_{f}-\delta c_{f}$, such that the demand for the brand product is given by

$$
D^{q}\left(p_{b}\right)=1-G\left(\hat{\theta}^{q}\left(p_{b}\right)\right) \quad \text { with } \quad \hat{\theta}^{q}\left(p_{b}\right):=\delta \frac{p_{b}-c_{f}}{q_{b}-q_{f}} .
$$

\footnotetext{
${ }^{6}$ In the original formulation of Bordalo, Gennaioli, and Shleifer (2013), the utility of a salient thinker is slightly different. We use the simpler formulation used by Bordalo, Gennaioli, and Shleifer (2016).
} 
If $q_{b} / p_{b}<\bar{q}_{\tilde{\mathcal{C}}} / \bar{p}_{\tilde{\mathcal{C}}}$, price is salient. A consumer of type $\theta$ purchases the brand product if $\delta \theta q_{b}-p_{b} \geq \delta \theta q_{f}-c_{f}$, such that the demand for the brand product is

$$
D^{p}\left(p_{b}\right)=1-G\left(\hat{\theta}^{p}\left(p_{b}\right)\right) \quad \text { with } \quad \hat{\theta}^{p}\left(p_{b}\right):=\frac{1}{\delta} \frac{p_{b}-c_{f}}{q_{b}-q_{f}} .
$$

As $\delta<1$, we have $D^{q}\left(p_{b}\right)>D^{p}\left(p_{b}\right)$ for all prices $p_{b}>c_{f}$. Therefore, the brand manufacturer strictly prefers a market in which quality rather than price is salient. With only the brand product and the fringe product in the choice set, however, quality is salient only if the price charged for the brand product is sufficiently low:

$$
\frac{q_{b}}{p_{b}}>\frac{\bar{q}_{\tilde{\mathcal{C}}}}{\bar{p}_{\tilde{\mathcal{C}}}} \Longleftrightarrow p_{b}<q_{b} \frac{c_{f}}{q_{f}} .
$$

Thus, according to (4), boosting demand by inducing quality salience comes at the cost of an upper bound for the price of the brand product. In fact, if the fringe produces a good with a relatively high quality-cost ratio, this salience-induced price ceiling severely limits the brand manufacturer's scope for choosing its product's price.

Extending the consumers' choice set to $\mathcal{C}=\left\{\left(q_{b}, p_{b}\right),\left(q_{f}, c_{f}\right),\left(q_{d}, p_{d}\right)\right\}=: \hat{\mathcal{C}}$ allows the brand manufacturer to choose the reference good indirectly as $\left(\bar{q}_{\hat{\mathcal{C}}}, \bar{p}_{\hat{\mathcal{C}}}\right)=$ $\left(\left(q_{b}+q_{f}+q_{d}\right) / 3,\left(p_{b}+c_{f}+p_{d}\right) / 3\right)$. Hence, adding the decoy good should help the brand manufacturer to achieve quality salience for its own product. Furthermore, with more than two products in the consumers' choice set, it might also be feasible to induce price salience for the fringe's product. In this case, a consumer of type $\theta$ purchases the high-quality brand product if $\delta \theta q_{b}-p_{b} \geq \theta q_{f}-\delta c_{f}$, such that the demand for the brand product is

$$
D^{d}\left(p_{b}\right)=1-G\left(\hat{\theta}^{d}\left(p_{b}\right)\right) \quad \text { with } \quad \hat{\theta}^{d}\left(p_{b}\right)=\frac{\delta p_{b}-c_{f}}{q_{b}-\delta q_{f}}
$$

As $\delta<1$, we have $D^{d}\left(p_{b}\right)>D^{q}\left(p_{b}\right)$ for all prices $p_{b}>c_{f}$. Hence, the best of the three possible scenarios for the manufacturer is to orchestrate the salience of the products such that (i) quality is salient for its own brand product and (ii) price is salient for the fringe product. In the remainder of the paper, we show how this can be achieved by appropriate design of the decoy good. 


\subsection{Design of the Decoy Good}

As outlined before, the brand manufacturer can offer the decoy good without costs. Moreover, as actual production of the decoy good is prohibitively costly, the manufacturer wants the decoy good not to be purchased by any consumer. The profit maximization problem thus amounts to:

$$
\max _{p_{b}, p_{d}, q_{d}}\left(p_{b}-c_{b}\right) D^{d}\left(p_{b}\right)
$$

subject to:

$$
\begin{aligned}
& \sigma\left(q_{b}, \bar{q}_{\hat{\mathcal{C}}}\right)>\sigma\left(p_{b}, \bar{p}_{\hat{\mathcal{C}}}\right) \\
& \sigma\left(q_{f}, \bar{q}_{\hat{\mathcal{C}}}\right)<\sigma\left(c_{f}, \bar{p}_{\hat{\mathcal{C}}}\right) \\
& \max \left\{u^{S}\left(q_{b}, p_{b} \mid \theta, \hat{\mathcal{C}}\right), u^{S}\left(q_{f}, c_{f} \mid \theta, \hat{\mathcal{C}}\right)\right\} \geq u^{S}\left(q_{d}, p_{d} \mid \theta, \hat{\mathcal{C}}\right), \forall \theta \in[\underline{\theta}, \bar{\theta}]
\end{aligned}
$$

The constraints $\left(\mathrm{SC}_{b}\right)$ and $\left(\mathrm{SC}_{f}\right)$ ensure, respectively, that quality is salient for the brand product and that price is salient for the fringe product. The constraint (DC) makes sure that no consumer actually buys the decoy good. We henceforth denote a decoy good that satisfies these constraints as an appropriate decoy good. We next show that, for the relevant set of prices, an appropriate decoy good always exists.

First, we establish that for any price $p_{b} \geq c_{b}$ of the brand product there exits a decoy good so that both salience constraints are satisfied.

Lemma 1. Suppose $p_{b} \geq c_{b}$. If $q_{d}=2 q_{f}-q_{b}$ and $p_{d}=2 p_{b}-c_{f}$, then $\left(S C_{b}\right)$ and $\left(S C_{f}\right)$ are both satisfied.

Proof. With $\left(q_{d}, p_{d}\right)=\left(2 q_{f}-q_{b}, 2 p_{b}-c_{f}\right)$, we have $\left(\bar{q}_{\hat{\mathcal{C}}}, \bar{p}_{\hat{\mathcal{C}}}\right)=\left(q_{f}, p_{b}\right)$. Constraint $\left(\mathrm{SC}_{b}\right)$ is satisfied because

$$
\sigma\left(p_{b}, \bar{p}_{\hat{\mathcal{C}}}\right)=\sigma\left(p_{b}, p_{b}\right)=\sigma\left(q_{f}, q_{f}\right)<\sigma\left(q_{b}, q_{f}\right)=\sigma\left(q_{b}, \bar{q}_{\hat{\mathcal{C}}}\right)
$$

where the first and the last equality hold by specification of the decoy good, the second equality holds by Assumption 2, and the inequality holds by Assumption 1 together with $q_{b}>q_{f}$. Likewise, constraint $\left(\mathrm{SC}_{f}\right)$ is satisfied because

$$
\sigma\left(q_{f}, \bar{q}_{\hat{\mathcal{C}}}\right)=\sigma\left(q_{f}, q_{f}\right)=\sigma\left(c_{f}, c_{f}\right)<\sigma\left(c_{f}, p_{b}\right)=\sigma\left(c_{f}, \bar{p}_{\hat{\mathcal{C}}}\right)
$$


where the first and the last equality hold by specification of the decoy good, the second equality holds by Assumption 2, and the inequality holds by Assumption 1 together with $p_{b} \geq c_{b}>c_{f}$.

According to Lemma 1, if the decoy good is chosen such that the reference good has the low quality of the fringe product and the high price of the brand product i.e., $\left(\bar{q}_{\hat{\mathcal{C}}}, \bar{p}_{\hat{\mathcal{C}}}\right)=\left(q_{f}, p_{b}\right)$ - quality is salient for the brand product and price is salient for the fringe product. ${ }^{7}$ As shown by the next lemma, this decoy good is also not purchased by any consumer type.

Lemma 2. Suppose $p_{b} \geq c_{b}$. If $q_{d}=2 q_{f}-q_{b}$ and $p_{d}=2 p_{b}-c_{f}$, then $(D C)$ is satisfied.

Proof. As $\delta<1, u^{S}\left(q_{d}, p_{d} \mid \theta, \hat{\mathcal{C}}\right) \leq \theta q_{d}-\delta p_{d}$. Moreover, by Lemma 1, quality is salient for the brand product. Therefore, a sufficient condition for the decoy not to be purchased is that

$$
\theta q_{d}-\delta p_{d} \leq \theta q_{b}-\delta p_{b} \quad \forall \theta \in[\underline{\theta}, \bar{\theta}]
$$

As $q_{f}<q_{b}$ and $c_{f}<c_{b} \leq p_{b}$, we have $q_{d}<q_{b}$ and $p_{d}>p_{b}$, i.e., the decoy good is dominated by the brand product. In consequence, (9) holds and (DC) is satisfied.

\subsection{Main Result}

Having established the existence of an appropriate decoy good, we now show that the brand manufacturer indeed benefits from the introduction of an appropriate decoy good.

Proposition 1. Introducing an appropriate decoy good strictly increases the brand manufacturer's profit. Specifically, charging $p_{b}^{*} \in \arg \max _{p_{b}}\left(p_{b}-c_{b}\right) D^{d}\left(p_{b}\right)$ and offering the decoy good $\left(q_{d}^{*}, p_{d}^{*}\right)=\left(2 q_{f}-q_{b}, 2 p_{b}^{*}-c_{f}\right)$ maximizes the brand manufacturer's profit.

\footnotetext{
${ }^{7}$ Lemma 1 does not provide necessary conditions regarding the specification of the decoy for the constraints $\left(\mathrm{SC}_{b}\right)$ and $\left(\mathrm{SC}_{f}\right)$ to be satisfied. In fact, there is a continuum of decoy specifications that satisfy the two salience constraints.
} 
Proof. If the constraints $\left(\mathrm{SC}_{b}\right),\left(\mathrm{SC}_{f}\right)$, and (DC) are satisfied, then consumers of type $\theta \geq \hat{\theta}^{d}\left(p_{b}\right)$ purchase the brand product and consumers of type $\theta<\hat{\theta}^{d}\left(p_{b}\right)$ purchase the fringe product. In this case, the optimal price for the brand product maximizes

$$
\Pi^{d}\left(p_{b}\right)=\left(p_{b}-c_{b}\right) D^{d}\left(p_{b}\right) .
$$

By Assumption 3, we have $\theta^{d}\left(c_{b}\right) \in(\underline{\theta}, \bar{\theta})$ and $0<D^{d}\left(c_{b}\right)<1$, such that $\Pi^{d}\left(p_{b}\right) \leq$ 0 for all $p_{b} \leq c_{b}$. As $d \Pi^{d}\left(p_{b}\right) /\left.d p_{b}\right|_{p_{b}=c_{b}}=D^{d}\left(c_{b}\right)>0$, the optimal price for the brand product must be strictly higher than $c_{b}$. Furthermore, $D^{d}\left(p_{b}\right)=0$ for $p_{b} \geq \frac{1}{\delta}\left[c_{f}+\bar{\theta}\left(q_{b}-\delta q_{f}\right)\right]$. Hence, effectively, the brand manufacturer chooses a price from the compact interval $\left[c_{f}, \frac{1}{\delta}\left[c_{f}+\bar{\theta}\left(q_{b}-\delta q_{f}\right)\right]\right]$. Continuity of $G(\cdot)$ then ensures the existence of an optimal price $p_{b}^{*} \in \arg \max _{p_{b}} \Pi^{d}\left(p_{b}\right)$. By Lemmas 1 and 2, the decoy good $\left(q_{d}, p_{d}\right)=\left(2 q_{f}-q_{b}, 2 p_{b}^{*}-c_{f}\right)$ then is indeed appropriate. From $D^{d}\left(p_{b}\right)>D^{q}\left(p_{b}\right)>D^{p}\left(p_{b}\right)$ for any $p_{b} \geq 0$ it follows immediately that offering the decoy good $\left(q_{d}, p_{d}\right)=\left(2 q_{f}-q_{b}, 2 p_{b}^{*}-c_{f}\right)$ is strictly preferable to not offering any decoy good for the brand manufacturer. Finally, from (5), it follows that $\Pi^{d}\left(p_{b}\right)$ is the same for all appropriate decoy goods. The decoy good $\left(q_{d}, p_{d}\right)=$ $\left(2 q_{f}-q_{b}, 2 p_{b}^{*}-c_{f}\right)$ hence maximizes the brand manufacturer's profit.

Thus, offering an appropriate decoy good allows the brand manufacturer to emphasize the advantage of its own product, the high quality, and - at the same time - to emphasize the unattractive feature of the competing product, its price. This boosts the demand for the brand product and allows the brand manufacturer to generate additional profits.

\section{Conclusion}

We have shown how a brand manufacturer can benefit from offering a decoy good if consumers are salient thinkers and we characterized the properties of the optimally designed decoy good. Interestingly, the specification of the optimal decoy good does not depend on the degree of the salience bias. Thus, offering this decoy good boosts demand even if the brand manufacturer is imperfectly informed about the degree of salient thinking or if there is heterogeneity among consumers regarding 
the extent of their salient thinking. The optimal price for the brand product, on the other hand, depends on the degree of salient thinking.

\section{References}

Adrian, N. C. (2016): "Price Discrimination and consumer Salience," mimeo, University of Bern, Switzerland.

Angner, E. (2012): A Course in Behavioral Economics. Palgrave Macmillan, New York.

ArIEly, D. (2008): Predictably Irrational - The Hidden Forces That Shape Our Decision. HarperCollins, New York.

Bordalo, P., N. Gennaioli, And A. Shleifer (2013): "Salience and Consumer Choice," Journal of Political Economy, 121(5), 803-843.

(2016): "Competition for Attention," The Review of Economic Studies, 83(2), 481-513.

Dertwinkel-Kalt, M. (2016): "Salience and Health Campaigns," Forum for Health Economics \& Policy, 19(1), 1-22.

Dertwinkel-Kalt, M., K. Köhler, M. R. LAnge, and T. Wenzel (2016): "Demand Shifts Due to Salience Effects: Experimental Evidence," Journal of the European Economic Association, forthcoming.

Huber, J., J. W. Payne, And C. Puto (1982): “Adding Asymmetrically Dominated Alternatives: Violations of Regularity and the Similarity Hypothesis," Journal of Consumer Research, 9(1), 90-98.

Huei-Chen, H., And L. Wen-Liang (2011): "Using Decoy Effects to Influence an Online Brand Choice: The Role of Price-Quality Trade-Offs.," CyberPsychology, Behavior \& Social Networking, 14(4), 235 - 239.

Inderst, R., AND M. ObRAdovits (2015): "Too Much Attention on Low Prices? Loss Leading in a Model of Sales with Salient Thinkers," 
http://www.cepr.org/active/publications/discussion_ papers /dp . php?dpno=10813, CEPR DP10813.

Tversky, A., And I. Simonson (1993): "Context-Dependent Preferences," Management Science, 39(10), 1179-1189. 